\section{sciendo \\ INFLUENCE OF THE SYMMETRY PLANE BOUNDARY CONDITION ON THE PLANING MULTIHULL CALM WATER RESISTANCE TEST. CFD TO TOWING TANK COMPARISON}

DOI 10.2478/ntpe-2018-0048

\author{
Maritime University of Szczecin, Poland
}

MSc. Eng. Karol Sugalski

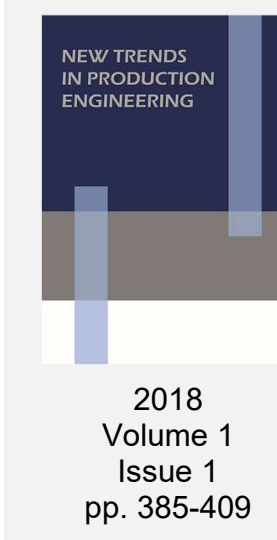

\begin{abstract}
This article present results of the comparison between numerical simulation (utilising Computational Fluid Dynamics) and towing tank experiment of the multihull vessel. Effect of the symmetry plane boundary condition on the resistance has been investigated. Reynolds-Averaged Navier Stokes equations with k- $\omega$ turbulence model has been used to calculate resistance of the hull with two degrees of freedom (2-DOF). Calculation has been done using OpenFOAM software package. Governing equations of fluid motion, together with the concept of the mesh and boundary condition has been presented in the first section of this work. Conclusion about calculating resistance of the multihull vessels has been made, after short presentation of the results.
\end{abstract}

Keywords: CFD, Computational Fluid Dynamics, high speed vessel design, multihull workboat

\title{
INTRODUCTION
}

Determining resistance of the hull using numerical methods gains popularity among naval architects. These types of calculations are no longer just the domain of research centers, despite the difficulties encountered by the analyst who compiles the numerical experiment. Apart from the difficulties bounded with the correct setting of the mathematical model describing the flow phenomenon, validation of results will be the most challenging task. This is particularly difficult when working on a prototype hull that is significantly different from existing units. For the evaluation of the results of computer simulations, theoretical knowledge of the physical phenomena is needed (Ferziger \& Perić, 2002; Lomax et al., 2001). A properly defined mathematical model should produce results that are close to the actual experiment, but it is likely that the apparently good results will deviate from the real ones, to the point, where they cannot be accepted for further analysis. The theoretical knowledge of the CFD operator allows him to decide whether the modeled phenomenon fully reflects the actual flow.

In CFD, boundary conditions are used to obtain the solution of the fluid motion equations in the discretized space (Blazek, 2005). One of the standard boundary conditions is the symmetry plane condition. Using this boundary reduces the number of computational grid elements, and thus reduces the RANSE simulation time (Abramowski \& Sugalski, 2017; Sugalski, 2014). Calculations using the boundary condition of symmetry are used in hydrodynamics, where the exact path of turbulences behind the hull does not significantly affect the results of the simulation (Szelangiewicz et al., 2010).

Catamarans, compared to the single-hull vessels of the same deck width, experience much less resistance due to the presence of two relatively narrow hulls (Suska, 2010). Hence, dual-hull units can serve as quick and efficient work boats providing equipment and supplies for offshore structures. The article presents results of the calculation of the planing catamaran, moving at the speed of 25 knots on calm water. Two different meshes has been studied, one with symmetry boundary condition, and one without this boundary condition. 
Numerical results are compared with model tests to verify the quality of the simulation. The simulation was based on the CFD code available in OpenFOAM version 3.0+ provided by ESI Group. The simulations captured the behavior of the two phases (water, air) and the reaction of the rigid body with two degrees of freedom. Sketch of the vessel is given in Fig. 1. Characteristic of the vessel are listed in Table 1.

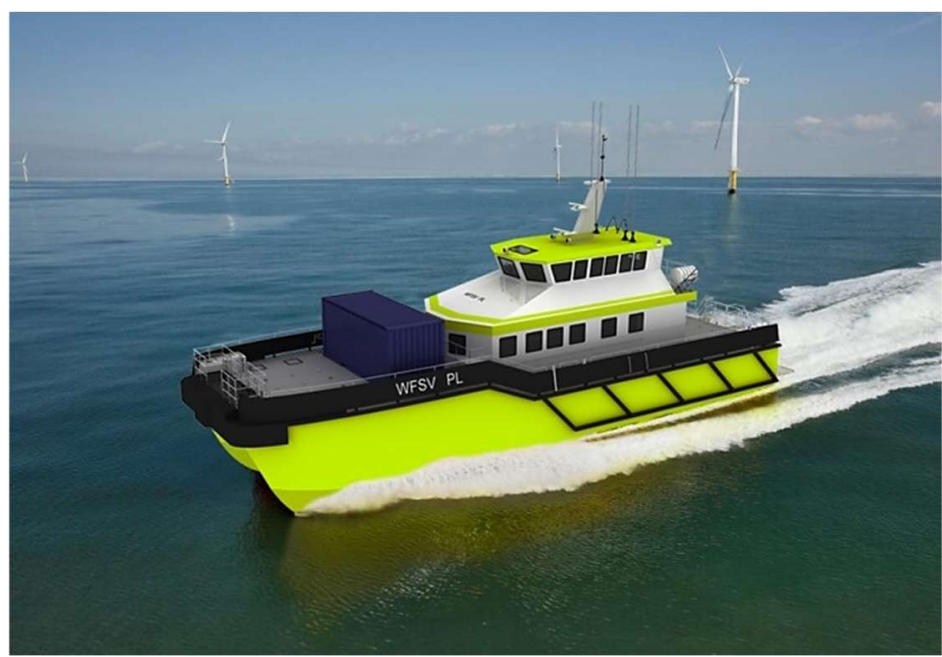

Fig. 1. Render of the calculated vessel.

Source: Courtesy of Mr. Valerio Costa.

Table 1

Essential ship data.

\begin{tabular}{|c|c|c|}
\hline Ship'sname & \multicolumn{2}{|c|}{ WFSV PL } \\
\hline \multirow{2}{*}{ Lenght $[\mathrm{m}]$} & Overall & Waterline \\
\hline & 26.27 & 24.7 \\
\hline \multirow{2}{*}{ Breadth [m] } & Overall & Individualhull \\
\hline & 8.0 & 2.6 \\
\hline \multirow{2}{*}{ Draught [m] } & AftPerpendicular & Front perpendicular \\
\hline & 0.883 & 1.2 \\
\hline \multirow{2}{*}{ Block coefficient } & Overall & Individualhull \\
\hline & 0.345 & 0.532 \\
\hline Displacement [t] & \multicolumn{2}{|c|}{82.22} \\
\hline Lcb (zero point at transom) [m] & \multicolumn{2}{|c|}{9.88} \\
\hline $\mathrm{Kb}[\mathrm{m}]$ & \multicolumn{2}{|c|}{0.779} \\
\hline Wettedsurface [m2] & \multicolumn{2}{|c|}{179.54} \\
\hline Transom deadriseangle $\left[{ }^{\circ}\right]$ & \multicolumn{2}{|c|}{0} \\
\hline Appendagescoefficient & \multicolumn{2}{|c|}{1} \\
\hline Froudenumber & \multicolumn{2}{|c|}{0,826} \\
\hline
\end{tabular}

Based on the theoretical lines, a real model has been developed in order to test it in the towing tank of the University of Genoa (Fig. 2).

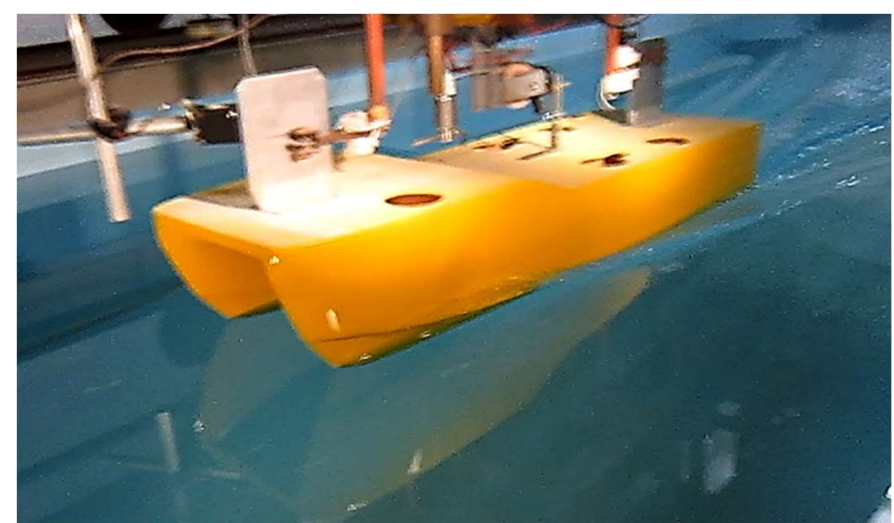

Fig. 2. Photography from the towing tank test.

Source: Courtesy of Mr. Valerio Costa. 


\section{GOVERNING EQUATIONS}

Navier-Stokes equations has been used to construct the mathematical model of the catamaran movement. Simulation involves a rigid body motion study in two continuous media whose density and viscosity has been chosen to match the water and air properties. It was assumed that both fluids would be incompressible. Due to the requirements of the free surface calculation method and motion of the rigid body, the time derivative has been included in the equations, but turbulence has been modeled with averaging (RANSE). Both fluids involved in the simulation were Newtonian fluids, i.e. it was assumed that the stress tensor in the fluid is equal to the tensor of the deformation speed (1).

$$
T=-\left(p+\frac{2}{3} \mu \operatorname{div} V\right) I+2 \mu D
$$

where:

$T$ - stress tensor,

$p$ - pressure,

$V$ - velocity vector,

$I$ - unity tensor,

$\mu$ - viscosity,

$D$ - rate of strain tensor.

In the simulation, the $\mathrm{k}-\omega$ turbulence model has been used because it is able to give a good approximation of the fluid behavior in the regions of adverse pressure (Suastika et al., 2017). Stern of a fast vessel is a natural region of the adverse pressure. Equations of motion, which describe the principle of mass preservation and the principle of momentum preservation, complemented by a turbulence model and recorded in a differential form with averaging take the form (2) - (5) (Ferziger \& Perić, 2002):

$$
\begin{gathered}
\frac{\partial\left(\rho \bar{u}_{l}\right)}{\partial x_{i}}=0 \\
\frac{\partial\left(\rho \bar{u}_{\imath}\right)}{\partial x_{i}}+\frac{\partial}{\partial x_{i}}\left(\rho \bar{u}_{\imath} \bar{u}_{J}+\rho \overline{u_{\imath}^{\prime} u_{J}^{\prime}}\right)=-\frac{\partial \bar{p}}{\partial x_{i}}+\frac{\partial \overline{\bar{l}_{l}}}{\partial x_{i}}+\rho \bar{f}_{l} \\
\frac{\partial(\rho k)}{\partial t}+\frac{\partial\left(\rho \bar{u}_{\imath} k\right)}{\partial x_{i}}=P_{k}-\rho \beta^{*} k \omega+\frac{\partial}{\partial x_{i}}\left[\left(\mu+\frac{\mu_{t}}{\sigma_{k}^{*}}\right) \frac{\partial \omega}{\partial x_{i}}\right] \\
\frac{\partial(\rho \omega)}{\partial t}+\frac{\partial\left(\rho \bar{u}_{\imath} \omega\right)}{\partial x_{i}}=\alpha \frac{\omega}{k} P_{k}-\rho \beta \omega^{2}+\frac{\partial}{\partial x_{i}}\left[\left(\mu+\frac{\mu_{t}}{\sigma_{k}^{*}}\right) \frac{\partial \omega}{\partial x_{i}}\right]
\end{gathered}
$$

where

$\rho$ - density,

$\overline{u_{l}}$ - velocity vector,

$\overline{u_{l}^{\prime}}$ - fluctuation part of velocity vector,

$\overline{\tau_{\imath \jmath}}$ - mean viscous stress tensor,

$\bar{f}_{l}$ - mass force,

$k$ - turbulent kinetic energy,

$P_{k}$ - rate of production of turbulent kinetic energy,

$\omega$ - inverse time scale.

I the $\mathrm{k}-\omega$ model, the eddy viscosity is expressed as (6):

$$
\mu_{t}=\rho \frac{k}{\omega}
$$

Coefficients of that model are (Ferziger and Perić, 2002):

$$
\alpha=\frac{5}{9}, \beta=0,075, \beta^{*}=0,09, \sigma_{k}^{*}=\sigma_{\omega}^{*}=2, \varepsilon=\beta^{*} \omega k .
$$

Another equation (7) has been used to recreate the free surface between two phases, this equation belong to the Volume of Fluid method (Kim and Park, 2017), where separate phases are calculated as one, using eq. (2) to (6), later to distinguish between phases, scalar quantity is introduced. If value of $\varphi=1$ the cell is filled with water, when $\varphi=0$ cell is filled with air.

$$
\frac{\partial \varphi}{\partial t}+\nabla \cdot\left(\varphi \overline{u_{l}}\right)=0
$$




\section{DOMAIN DISCRETIZATION}

Two separate meshes has been prepared. First, with standard approach (Ozdemir and Barlas, 2017), where the symmetry plane boundary condition is present (Fig. 3). Second, where entire hull has been recreated (Fig. 4).

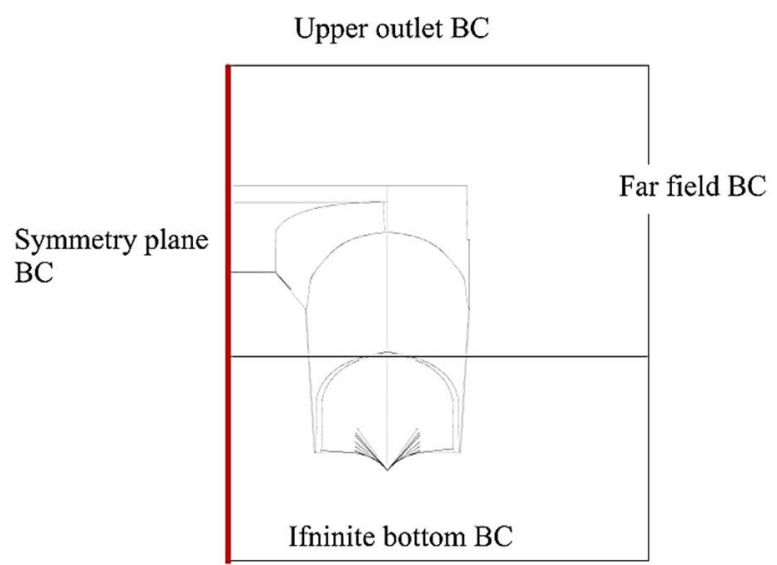

Source: own elaboration.

Fig. 3. Domain with symmetry plane boundary condition.

Both grids has been made using hexahedral mesh generator. They are hex dominant, only near transition region between hull and the rest of domain tetrahedral and prism elements exists. The boundary layer region near the hull surface has been prepared in such way, that $\mathrm{y}^{+}$value was around 100 . First mesh, with symmetry plane, has been created using approximately 400000 elements. It is considered as a medium mesh it the sense of its density. Second one consist of 3,5 millions of elements and therefore it is considered as fine grid.

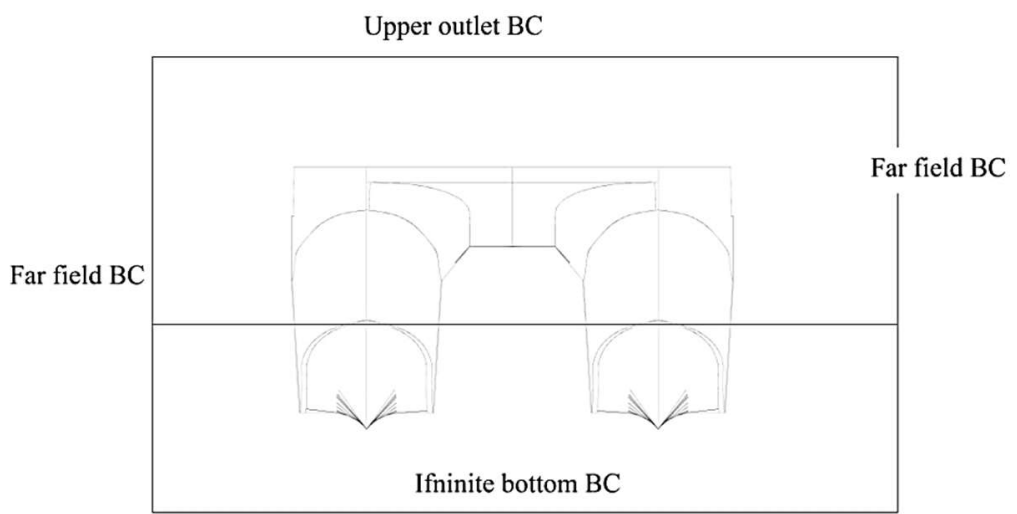

Fig. 4. Domain without symmetry plane boundary condition.

Source: own elaboration.

To catch phenomenon of the planing hull movement, dynamic mesh technique has been used. Cells near the hull surface are free to move and rotate with respect to two degrees of freedom. Translation on z-axis and rotation around y-axis has been allowed (Fig. 5).

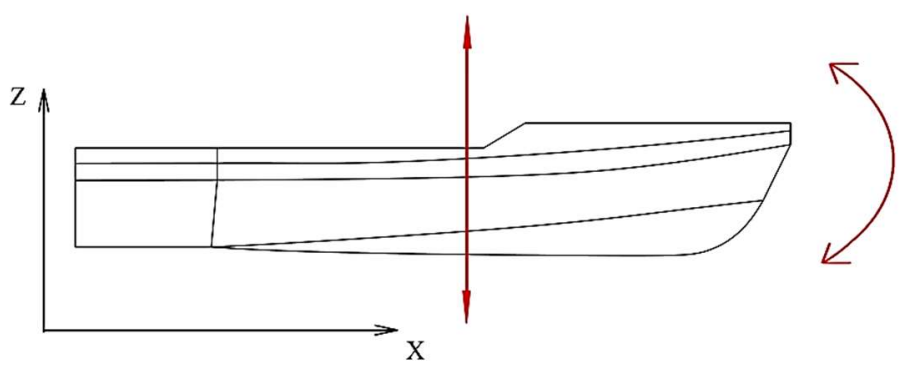

Fig. 5. Sketch of the allowable motion of the hull during simulation. Source: own elaboration. 
To avoid loosing orthogonality of cells near hull surface during rotation of the vessel, transition zone has been defined, where crucial cells stays intact.

Overall scale factor for this simulation has been set to $\lambda=20$. This value was restricted by the towing tank dimensions. All boundaries of both domains has been set away from hull in order to minimize influence of possible reflections.

Boundary conditions on all sides of the domain has been set to standard values in this type of simulation. At the inlet, value of speed of the vessel has been prescribed. Purpose of all other boundaries are to mimic permeable walls, to allow free outflow and inflow of water and air during the simulation. In order to safe computational time and costs, symmetry plane has been introduced. In cases where monohull is investigated this kind of boundary condition gives good agreement with experiments (Abramowski and Sugalski, 2017; Szelangiewicz et al., 2010).

\section{RESULTS}

Input values for the simulation are listed in Table 2. Comparison of the towing tank experiment and the numerical simulation are listed in Table 3.

Table 2

Velocity of the hull and fluids properties.

\begin{tabular}{|c|c|c|c|}
\hline \multirow{2}{*}{ Velocity } & Model scale [m/s] & Real scale [kts] & Froudenumber \\
\cline { 2 - 3 } & 2.88 & 25 & \multirow{2}{*}{0.826} \\
\hline Reynold'snumber & $3.5 \mathrm{e}+6$ & - & \multicolumn{2}{|c|}{ Kinematicviscosity $\left[\mathrm{m}^{2} / \mathrm{s}\right]$} \\
\hline \hline \multirow{2}{*}{ Water } & Density $\left[\mathrm{kg} / \mathrm{m}^{3}\right]$ & \multicolumn{2}{|c|}{$1 \mathrm{e}-6$} \\
\cline { 2 - 4 } & 998 & \multicolumn{2}{|c|}{$1.48 \mathrm{e}-5$} \\
\hline Air & 1 & \multicolumn{2}{|c}{} \\
\hline
\end{tabular}

Table 3

Comparison of the results from simulation and towing tank experiment.

\begin{tabular}{|c|c|c|c|c|c|}
\hline Calculationmethod & \multicolumn{2}{|l|}{$\begin{array}{l}\text { Total resistance } \\
\text { of bare hull }[\mathrm{N}]\end{array}$} & $\begin{array}{l}\text { Lift } \\
\text { force } \\
{[N]}\end{array}$ & $\begin{array}{c}\text { Trim angle } \\
\text { (+ on stern) } \\
\text { [deg] }\end{array}$ & $\begin{array}{c}\text { Wettedsurface } \\
{\left[\mathrm{m}^{2}\right]}\end{array}$ \\
\hline \multirow{3}{*}{$\begin{array}{l}\text { RANSE Method } \\
\text { Semi-Hull }\end{array}$} & \multicolumn{2}{|l|}{10.62} & 100.64 & 1.90 & 0.420 \\
\hline & Pressureresistance [N] & 4.360 & & & \\
\hline & Visciousresistance [N] & 6.264 & & & \\
\hline \multirow{3}{*}{$\begin{array}{l}\text { RANSE Method } \\
\text { Entire Hull }\end{array}$} & \multicolumn{2}{|l|}{12,89} & 100.65 & 1.90 & 0.401 \\
\hline & Pressureresistance $[\mathrm{N}]$ & 6.056 & & & \\
\hline & Visciousresistance $[\mathrm{N}]$ & 6.832 & & & \\
\hline $\begin{array}{l}\text { Model Towing } \\
\text { Tank Test }\end{array}$ & \multicolumn{2}{|l|}{13.29} & $\begin{array}{l}\text { No } \\
\text { data }\end{array}$ & 1.46 & No data \\
\hline
\end{tabular}

Convergence process of the transient simulation of entire hull is given in Fig. 6 .

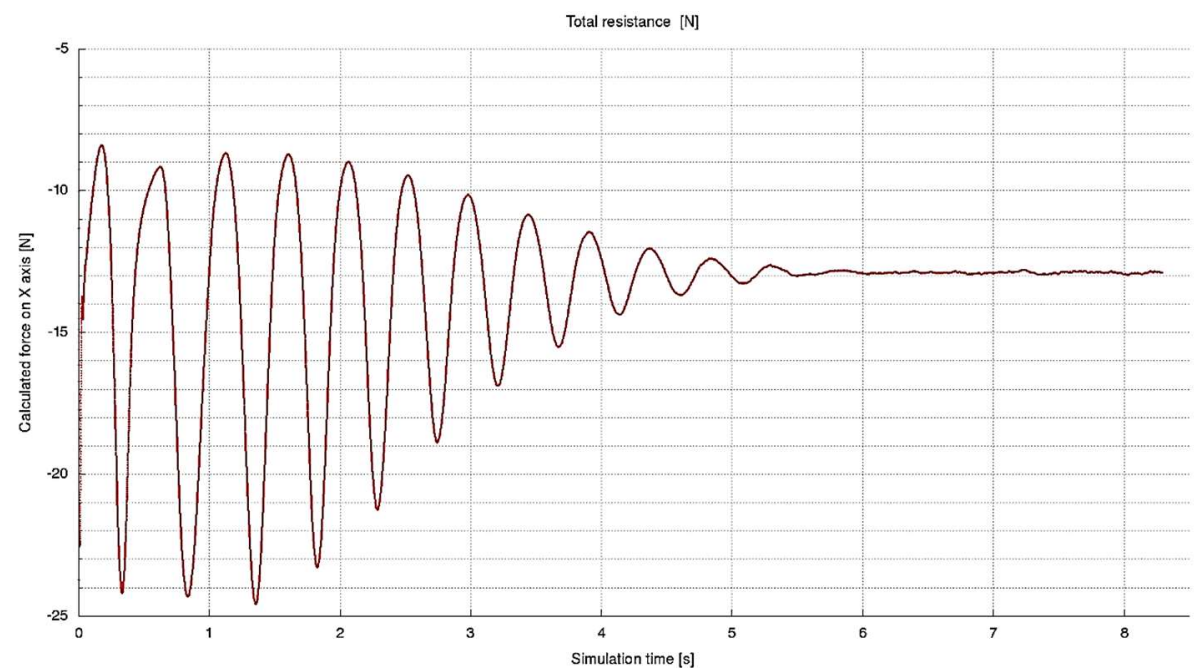

Fig. 6. Resistance of the hull from simulation without symmetry plane boundary condition.

Source: own elaboration. 
In case of transient simulation, convergence can be measured thru overall result of the simulation, rather than analyze of the residuals.

Wetted surface from the entire hull simulation is given in Fig. 7. wave elevation in Fig. 8.

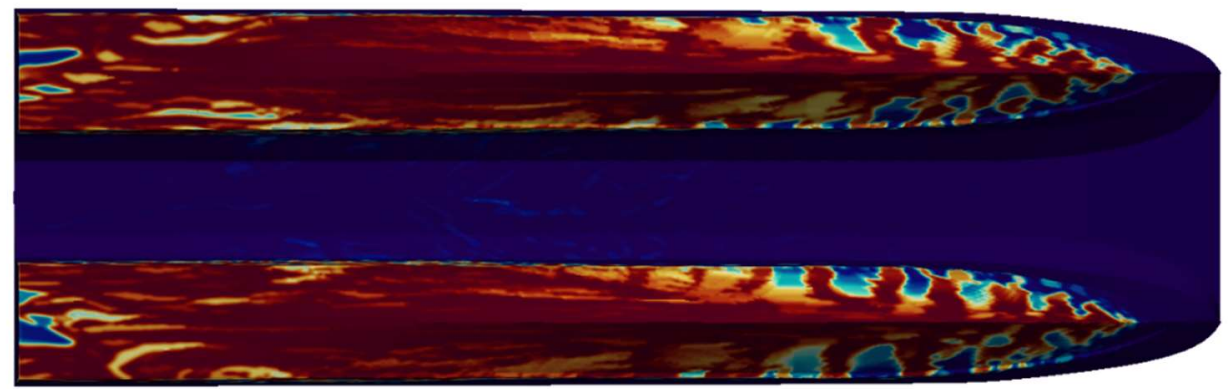

Fig. 7. Wetted surface obtained from simulation of the entire hull. Grey - water, black - air.

Source: own elaboration.

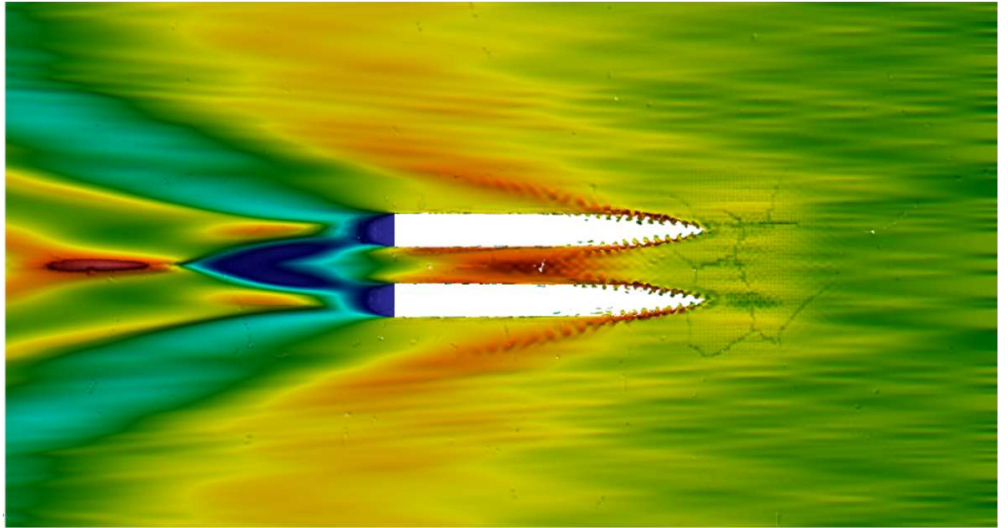

Fig. 8. Wave elevation obtained from entire hull calculation. Dark grey - wave crest.

Source: own elaboration.

\section{CONCLUSIONS}

Results obtained using standard grid with presence of the symmetry plane boundary condition differs significantly from towing tank experiment. Mesh in symmetry plane case was coarse, but fine enough to correct predict viscosity resistance. Big differences emerge from the pressure resistance. It is highly possible, that symmetry boundary condition cannot predict impact and interference of waves between hulls. According to (Blazek, 2005), following gradients have to vanish to fulfill symmetry boundary condition:

- gradient of a scalar quantity normal to the boundary,

- gradient of the tangential velocity normal to the boundary,

- gradient of the normal velocity along the boundary.

If there is no change in tangential velocity normal to the boundary, wave generated between hulls cannot rise, because there is no wave from the other side to interfere. Symmetry boundary condition behave like there is no other hull, on the other side of the symmetry plane.

Results from Table 3 show that when entire hull is calculated, pressure resistance is bigger, probably due to interference of the mid hull waves. Calculation from this simulation differs only by $3 \%$ from experiment. Error from the standard approach (with symmetry plane) is about $20 \%$. Predicting resistance of the multihull vessel by CFD methods should be conducted on a mesh without symmetry plane boundary condition. Using symmetry boundary condition in such case can lead to underestimate of the resistance, because of inappropriate modeling of the mid hull waves interference. 


\section{ACKNOWLEDGMENTS}

Simulation presented in this paper has been made on the hull designed and provided by Mr. Valerio Costa. Comparison to the experimental data has been possible by courtesy of Towing Tank at Genoa University. Special thanks to Prof. Dario Boote from the Department of Electrical, Electronic, Telecommunications Engineering and Naval Architecture (DITEN) of the University of Genova, for supervising towing tank experiments and design of the hull done by Mr. Costa.

\section{REFERENCES}

Abramowski, T., and Sugalski, K. (2017). Energy saving procedures for fishing vessels by means of numerical optimization of hull resistance. Scientific Journals of the Maritime University of Szczecin 121, pp. 19-27.

Blazek, J. (2005). Computational Fluid Dynamics: Principles and applications. Elsevier.

Ferziger, J.H., and Perić, M. (2002). Computational Methods for Fluid Dynamics. Berlin: Springer-Verlag.

Kim, G.H., and Park, S. (2017). Development of a numerical tool for efficient and robust prediction of ship resistance. International Journal of Naval Architecture and Ocean Engineering 9, pp. 537-551.

Lomax, H., Pulliam, T.H., and Zingg, D.W. (2001). Fundamentals of Computational Fluid Dynamics. Berlin: Springer-Verlag.

Ozdemir, Y.H., and Barlas, B. (2017). Numerical study of ship motions and added resistance in regular incident waves of KVLCC2 model. International Journal of Naval Architecture and Ocean Engineering 9, pp. 149-159.

Suastika, K., Hidayat, A., and Riyadi, S. (2017). Effects of the application of a stern foil on ship resistance: a case study of an Orela crew boat. International Journal of Technology 8, pp. 1266-1275.

Sugalski, K. (2014). Fishing vessel hull design and towing resistance calculation by the CFD methods. Scientific Journals of the Maritime University of Szczecin.

Suska, W.L. (2010). Motorówki i małe kutry motorowe - wypornościowe, półwypornościowe/półślizgowe i ślizgowe. Gdańsk: Fundacja Promocji Przemysłu Okrętowego i Gospodarki Morskiej.

Szelangiewicz, T., Żelazny, K., and Abramowski, T. (2010). Numerical analysis of effect of asymmetric stern of ship on its screw propeller efficiency. Polish Maritime Research 17, pp. 13-16. 